DOI: https://doi.org/10.47405/mjssh.v6i12.1180

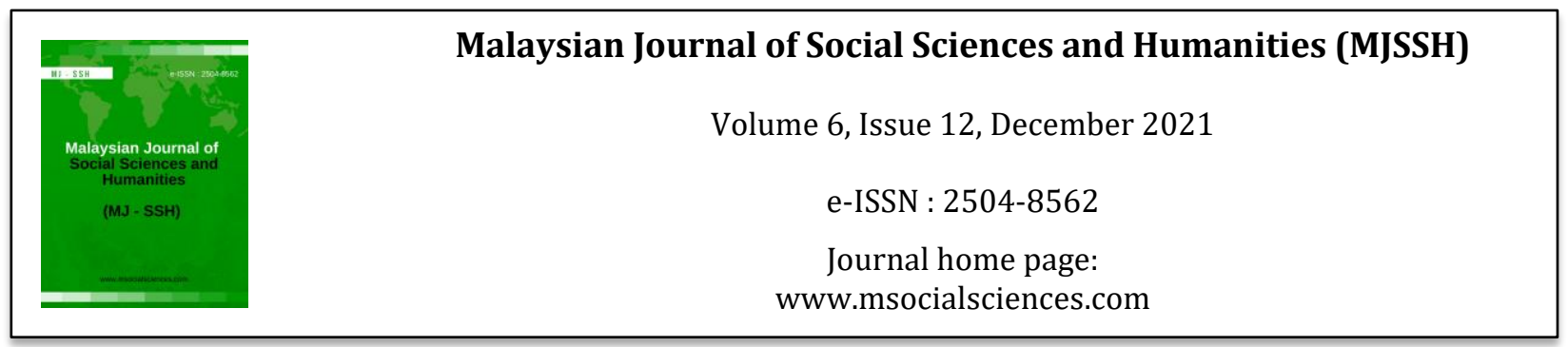

\title{
Kesan Kepercayaan dan Efikasi Kendiri ke atas Pengajaran Pendidikan Islam Berintegrasikan KBAT di Malaysia: Satu Analisis Multilevel
}

\author{
Haswani Dzul', Zaharah Hussin', Abdul Muhsien Sulaiman' \\ 1 Jabatan Asas Pendidikan dan Kemanusiaan, Fakulti Pendidikan, Universiti Malaya (UM), Malaysia \\ Correspondence: Haswani Dzul (haswanidzul@gmail.com)
}

\begin{abstract}
Abstrak
Kajian ini mengkaji hubungan antara kepercayaan, efikasi kendiri, dan pengajaran Pendidikan Islam berintegrasikan Kemahiran Berfikir Aras Tinggi (KBAT). Seramai 642 orang GPI dari 112 buah sekolah terlibat dalam tinjauan ini. Analisis secara multilevel dijalankan untuk meneroka bagaimana pemboleh ubah peringkat kumpulan (kepercayaan) memberi kesan ke atas pemboleh ubah peringkat individu (efikasi kendiri dan amalan pengajaran Pendidikan Islam berintegrasikan KBAT). Dapatan menunjukkan kepercayaan dan efikasi kendiri berhubung secara positif dan signifikan ke atas pengajaran Pendidikan Islam berintegrasikan KBAT. Dapatan kajian juga menunjukkan efikasi kendiri berperanan sebagai mediator terhadap hubungan antara kepercayaan dan pengajaran Pendidikan Islam berintegrasikan KBAT guru Pendidikan Islam. Implikasi dapatan kajian ini diharap dapat membantu memupuk sikap saling percaya dalam kalangan GPI dan komuniti sekolah serta membantu dalam memperbaiki amalan pengajaran mereka.
\end{abstract}

Kata kunci: kepercayaan, efikasi kendiri, kemahiran berfikir aras tinggi

\section{The Impact of Trust and Self-Efficacy on Teaching of HOTS in Islamic Education: A Multilevel Analysis}

\begin{abstract}
This study examines the relationship between trust, self-efficacy, and teaching practices of Higherorder Thinking Skills (HOTS) in Islamic Education. A total of 642 Islamic Education Teachers from 112 schools responded and participated in the survey. Multilevel analysis was conducted to investigate how group level variables (trust) affect individual level variables (self-efficacy and teaching practices of HOTS in Islamic Education). The findings indicated that trust and self-efficacy could positively and significantly account for variances of the teaching practices of HOTS in Islamic Education. The findings of the study also showed that self-efficacy significantly mediates the relationship between trust and the teaching practices of HOTS in Islamic Education. The implications of this study are expected to foster the mutual trust between Islamic Education Teachers and school community as well as to improve their teaching practices.
\end{abstract}

Keywords: trust, self-efficacy, higher-order thinking skills 


\section{Pengenalan}

Kurikulum Pendidikan Islam di Malaysia memberi penekanan kepada konsep ilmu yang dibawa oleh Imam al- Ghazali (1988). Konsep ilmu ini bukan sahaja merangkumi aspek pengetahuan dan kemahiran, tetapi juga aspek nilai. (Bahagian Pembangunan Kurikulum, 2015). Justeru, Guru Pendidikan Islam (GPI) mempunyai peranan yang amat besar bukan sekadar menyampaikan ilmu, malah perlu membentuk peribadi mulia dalam diri murid sebagaimana yang digariskan dalam Falsafah Pendidikan Islam (FPI). GPI perlu memahami dan menghayati FPI ini agar amanah untuk membentuk generasi berilmu, beriman, dan berakhlak mulia dapat dilaksanakan dengan memberikan pengajaran dan pembelajaran yang berkesan. Ilmu Pendidikan Islam yang disampaikan secara berkesan di dalam bilik darjah, akan memberi impak kepada pembentukan modal insan yang sempurna dalam diri murid (Kamarul Azmi Jasmi, 2010).

Oleh itu, amat penting untuk GPI mempelbagaikan kaedah dan strategi pengajaran yang lebih kreatif dan menekankan elemen KBAT sesuai dengan kehendak Pembelajaran Abad ke-21 (PAK-21). Pengajaran berintegrasikan KBAT seharusnya diberikan lebih tumpuan dalam Pendidikan Islam memandangkan KBAT adalah sangat relevan dengan kehendak semasa dan dapat membantu murid untuk lebih memahami hikmah di sebalik setiap amalan, dalil-dalil, dan aplikasinya dalam kehidupan seharian masyarakat Islam (Wan Mat Sulaiman, 2011) serta memperluaskan ilmu Pendidikan Islam merentasi bidang ilmu yang lain (Wan Ali Akbar Wan Abdullah et al., 2020).

Namun, aspek aplikasi pengintegrasian KBAT dalam amalan pengajaran dikhuatiri kurang berupaya memenuhi kualiti pendidikan yang diharapkan dan perlu kepada cadangan penambahbaikan khususnya dalam Pendidikan Islam (Mohd Zaidi Mohd Zeki et al., 2021). Hal ini kerana, kajian-kajian lepas menunjukkan amalan pengajaran berintegrasikan KBAT dalam Pendidikan Islam masih berada pada tahap yang rendah dan sederhana (Haswani Dzul, 2017; Mohamad Zaidir Zainal Abidin \& Kamisah Osman, 2017; Norasmahani Nor et al., 2015; Wan Mat Sulaiman, 2011) kerana wujudnya beberapa faktor kelemahan untuk mengintegrasikan elemen KBAT dalam amalan pengajaran. Selain faktor pengetahuan dan kemahiran guru dalam mengintegrasikan elemen KBAT yang minima (Nursafra Mohd Zhaffar, 2017; Shamilati Che Seman et al., 2017), dapatan kajian juga menunjukkan faktor sikap guru yang kurang keyakinan menyebabkan pengajaran berintegrasikan KBAT juga berada pada tahap sederhana (Mohamad Zaid Mustafa et al., 2018; Nur Hawa Hanis Abdullah \& Ghazali Darusalam, 2018). Selain itu, persepsi guru yang menganggap bahawa elemen KBAT ini sukar untuk diterapkan di dalam bilik darjah dan hanya sesuai diaplikasikan kepada murid-murid yang berpencapaian tinggi sahaja (Abdul Talib Hashim et al., 2015; Onosko, 1991; Zohar et al., 2001; Zohar \& Schwartzer, 2005) turut menjadi halangan untuk guru mengintegrasikan elemen KBAT dalam pengajaran mereka. Kurangnya kepercayaan guru terhadap keupayaan murid ini menyebabkan guru-guru sukar untuk mengaplikasikan sesuatu inovasi atau pengajaran yang baru (Cai \& Tang, 2021; Goddard \& Goddard, 2001).

Berdasarkan faktor-faktor di atas, kajian-kajian lepas mendapati faktor sikap dan kepercayaan turut menjadi indikator penting bagi memastikan keberkesanan pengajaran berintegrasikan KBAT (Mohd Syaubari Othman, 2019; Wan Amirah Wan Ismail et al., 2016; Zohar, 2004). Justeru, kajian ini mencadangkan agar persepsi negatif guru terhadap KBAT dapat diubah melalui persekitaran kepercayaan di sekolah yang juga dilihat berpotensi untuk mengubah sikap guru menjadi lebih berefikasi (Gray, 2016). Kajian-kajian lepas menunjukkan pembentukan persekitaran sekolah yang saling percaya dan peningkatan efikasi kendiri (EK) guru adalah langkah yang efektif untuk memperbaiki kualiti pengajaran guru dan pencapaian murid (Klassen \& Tze, 2014; Noornajihan Jaafar, 2014; Tschannen-Moran, 2004; Wahlstrom \& Louis, 2008). Kedua-dua pemboleh ubah ini dilihat dapat memaksimumkan amalan pengajaran guru di bilik darjah. Oleh itu, efikasi kendiri dapat berperanan sebagai mediator antara hubungan kepercayaan dan pengajaran guru. EK juga dilihat lebih sesuai memainkan peranan sebagai mediator dalam kajian yang berbentuk tingkah laku (Bandura, 1986; Chan et al., 2008; Sukserm \& Takahashi, 2012; Xanthopoulou et al., 2007).

Walaupun terdapat kajian terdahulu yang menguji EK sebagai mediator kepada kepercayaan (Yin et al., 2013), tetapi tidak melihat kesannya kepada amalan pengajaran guru. Malah, hubungan kausal 
antara kepercayaan dan efikasi guru juga kurang jelas dan jarang diterokai dalam literatur (Yin et al., 2019; Yin et al., 2013). Kajian review efikasi guru selama 12 tahun oleh Klassen et al. (2011) menunjukkan kajian mengenai sumber EK dan kaitannya dengan amalan pendidikan masih kurang diberi perhatian. Malah kajian EK di Malaysia juga masih terhad terutama dalam bidang Pendidikan Islam (Absha Atiah Abu Bakar \& Mohd Isa Hamzah, 2019; Noornajihan Jaafar \& Ab Halim Tamuri, 2013). Di Malaysia pula, kajian berkaitan kepercayaan dalam organisasi sekolah dilihat sangat terhad dan lebih berfokus kepada kepercayaan terhadap pentadbir (Jumadi Musa et al., 2020; Ling Ying Leh, 2016) dan melihat hubungan dengan pemboleh ubah yang lain (Choong Yuen Onn et al., 2018). Justeru, kajian ini bertujuan untuk menguji kesan kepercayaan dan efikasi kendiri ke atas pengajaran Pendidikan Islam berintegrasikan KBAT, serta menguji efikasi kendiri sebagai mediator terhadap hubungan di antara kepercayaan dan pengajaran Pendidikan Islam berintegrasikan KBAT. Kajian ini menggunakan pendekatan multilevel modeling untuk melihat kesan pemboleh ubah aras tinggi (upper level) ke atas pemboleh ubah aras rendah (lower level) secara lebih tepat. Secara tidak langsung, kajian ini dapat mengisi jurang terhadap kajian-kajian berkaitan kepercayaan di Malaysia yang menggunakan pendekatan secara aras tunggal (single level).

\section{Sorotan Literatur}

\section{Hubungan kepercayaan dengan pengajaran guru dan efikasi kendiri}

Kepercayaan dalam kajian ini merujuk kepada tingkah laku, komunikasi, perkataan, janji, kenyataan secara lisan atau bertulis, sikap, dan kesanggupan seseorang individu atau kumpulan untuk mengambil risiko dengan meletakkan keyakinan bahawa individu yang lain akan melakukan yang terbaik kepada pihak yang lain berdasarkan elemen seperti suka membuat kebajikan, boleh dipercayai, cekap, jujur, dan terbuka (Hoy et al., 2006; Hoy \& Tschannen-Moran, 1999; Tschannen-Moran \& Hoy, 1998). Kajian berkaitan nilai kepercayaan dalam organisasi sekolah sebenarnya telah muncul dalam literature sejak tiga dekad yang lalu. Kepercayaan diperlukan untuk mendapatkan kerjasama dan komunikasi yang efektif dalam sesebuah organisasi (Hoy \& Tschannen-Moran, 1999) dan menjadi elemen penting dalam mewujudkan sekolah yang efektif dari segi budaya kerja dan pembelajaran (Tschannen-Moran \& Hoy, 1998).

Kajian-kajian yang dijalankan menunjukkan bahawa kepercayaan mempunyai kaitan dengan pencapaian murid (Tschannen-Moran, 2004); dapat membantu membentuk iklim sekolah yang positif (Bryk \& Schneider, 2003); membantu menggalakkan amalan pengajaran guru menjadi lebih berkualiti (Wahlstrom \& Louis, 2008); membantu guru untuk mencari strategi pengajaran yang baru (Goddard \& Goddard, 2001); memberikan rasa selamat kepada guru untuk bereksperimen dengan amalan pengajaran yang baru (Bryk \& Schneider, 2003); mempengaruhi prestasi pengajaran guru (Happy Fitria, 2018; Liou et al., 2016); serta menggalakkan guru untuk berinovasi (Cai \& Tang, 2021). Malah, untuk melaksanakan sesuatu pengajaran berintegrasikan elemen KBAT dengan jayanya, persepsi atau kepercayaan guru menjadi antara faktor penting (Zohar, 2004).

Selain itu, iklim sekolah yang positif dan saling percaya dapat mempengaruhi tahap EK guru. Kajiankajian lepas menunjukkan terdapat hubungan korelasi yang positif antara kepercayaan dengan efikasi guru (Dale, 2004; Goddard et al., 2000; Hoy \& Tschannen-Moran, 1999; Lee et al., 2011; Okpogba, 2001; Paxton et al., 2014). Dapatan lepas memberi kesimpulan bahawa guru-guru di sekolah yang mempunyai tahap kepercayaan yang tinggi dalam kalangan mereka, cenderung untuk mempunyai efikasi guru yang tinggi. Dapatan kajian menjelaskan bahawa kepercayaan amat diperlukan untuk mengembangkan profesionalisme, efikasi, dan komitmen guru kepada murid.

\section{Hubungan efikasi kendiri dengan pengajaran guru}

Efikasi kendiri adalah kepercayaan, persepsi, dan keyakinan guru terhadap keupayaan dan kemampuan diri untuk mengatur dan melaksana tindakan yang sewajarnya untuk mencapai kejayaan dalam pengajaran, berdepan situasi mencabar, menghadapi kegagalan, dan tekanan (Bandura, 1977; Goddard \& Goddard, 2001; Tschannen-Moran, 1998). Berdasarkan teori kognitif sosial, tindakan yang 
dilakukan oleh individu dipengaruhi oleh kekuatan efikasi (Bandura, 1997). Oleh itu, sebarang keputusan yang dibuat oleh guru berkaitan amalan bilik darjah dipengaruhi oleh rasa efikasi terhadap pengajaran (Goddard et al., 2004). EK mampu menjadikan guru sentiasa bersikap positif terhadap pengajaran, terhadap dirinya, dan muridnya. EK mendorong guru merancang pembelajaran murid, menetapkan matlamat pembelajaran bersama murid, dan mengenal pasti strategi terbaik untuk mencapai matlamat tersebut (Ashton, 1984).

Dapatan kajian Wolters dan Daugherty (2007) membuktikan bahawa EK mempengaruhi jenis amalan pengajaran yang akan dipraktikkan oleh guru. Guru yang mempunyai keyakinan yang tinggi untuk mengubah pengajaran dan strategi penilaian untuk disesuaikan dengan murid, cenderung mempraktikkan amalan pengajaran yang memfokuskan peningkatan prestasi murid, mengatasi segala cabaran, dan berusaha belajar sebanyaknya. Kajian meta-analisis oleh Klassen dan Tze (2014) turut menyimpulkan hasil dapatannya bahawa EK guru sangat berkaitan dengan prestasi pengajaran guru juga merapatkan jurang pencapaian murid Goddard et al. (2017). Kajian sintesis terhadap 40 tahun kajian berkaitan EK memberi bukti secara empirikal bahawa EK bukan sahaja memberi kesan terhadap amalan guru, kualiti bilik darjah, dan akademik murid, tetapi turut memainkan peranan penting terhadap kesejahteraan psikologi guru seperti kepuasan kerja, komitmen guru, dan mengurangkan burnout dan tekanan (Zee \& Koomen, 2016). Guru yang berefikasi tinggi kurang tertekan apabila berhadapan dengan sebarang perubahan dalam kurikulum (Putwain \& Embse, 2018) serta bertoleransi terhadap salah laku murid (Gholami et al., 2016).

Kesimpulannya, berdasarkan dapatan-dapatan kajian lepas, pengkaji berpendapat pemboleh ubah kepercayaan berupaya berfungsi sebagai salah satu faktor yang mendorong GPI untuk mempraktikkan pengajaran Pendidikan Islam berintegrasikan KBAT serta menjadi sumber kepada efikasi kendiri GPI sebagaimana yang dijelaskan oleh (Bandura, 1997). Manakala, EK pula dilihat mampu mempengaruhi tingkah laku guru dalam merancang, memilih, dan mengaplikasikan amalan pengajaran efektif yang dapat memberi kesan kepada prestasi murid. Oleh itu, pengkaji berpendapat bahawa EK juga dapat mempengaruhi GPI dalam mempraktikkan amalan pengajaran berintegrasikan elemen KBAT.

\section{Metod Kajian}

Reka bentuk kajian ini ialah kajian tinjauan keratan rentas (cross sectional) yang menggunakan pendekatan kuantitatif untuk mengumpul dan menganalisis data.

\section{Populasi dan Pensampelan}

Populasi dalam kajian ini adalah guru-guru Pendidikan Islam sekolah rendah di Malaysia. Oleh kerana kajian ini melibatkan populasi yang besar dan kawasan geografi yang luas, maka pensampelan kelompok pelbagai peringkat (multistage cluster sampling) digunakan bagi menentukan sampel kajian (Cohen et al., 2018; Creswell, 2012). Populasi dikelompokkan kepada lima zon, kemudian sebuah negeri akan dipilih dari setiap zon menggunakan pensampelan rawak mudah. Seramai 642 orang GPI melibatkan 112 buah sekolah dipilih secara rawak sebagai sampel kajian iaitu $25 \%$ dari Zon Tengah, $23.2 \%$ dari Zon Selatan, $21.4 \%$ dari Zon Timur, $16.1 \%$ dari Zon Utara, dan $14.3 \%$ dari Zon Malaysia Timur.

\section{Instrumen Kajian}

Instrumen kajian yang digunakan ialah soal selidik yang diedarkan melalui pautan google form. Pengkaji terlebih dahulu memohon kebenaran menjalankan kajian daripada Bahagian Perancangan dan Penyelidikan Dasar Pendidikan dan Jabatan Pendidikan Negeri bagi negeri-negeri yang terlibat. Penyertaan responden adalah secara sukarela. Bagi menjaga kerahsiaan responden kajian, responden tidak perlu mendedahkan pengenalan diri dalam borang kaji selidik tersebut, malah pengenalan diri responden juga tidak akan dapat dikesan oleh mana-mana pihak. 
Pemboleh ubah kepercayaan dalam kajian ini diukur dengan menggunakan soal selidik Omnibus TScale (Hoy \& Tschannen-Moran, 2003) yang telah diterjemahkan ke dalam bahasa Melayu. Instrumen asal terdiri daripada 26 item, selepas analisis faktor penerokaan (EFA) dijalankan tiga faktor dikekalkan tetapi tiga item digugurkan kerana factor loading $<0.45$ dengan keseluruhan penjelasan varian adalah sebanyak $61.1 \%$. Seterusnya, analisis faktor pengesahan (CFA) dijalankan, tiga item telah digugurkan. Analisis faktor pengesahan sekali lagi dijalankan ke atas model yang telah dimodifikasi dan hasil menunjukkan indeks kesepadanan yang lebih baik $(R M S E A=0.63 ; G F I=0.91$; $C F I=0.94 ; T L I=0.94) .20$ item dikekalkan bagi mengukur dimensi kepercayaan kepada pentadbir (5 item), kepercayaan kepada rakan sekerja (7 item), dan kepercayaan kepada ibu bapa dan murid (8 item). Nilai pekali Alpha Cronbach bagi ketiga-tiga dimensi ialah 0.82, 0.92, dan 0.91.

Pemboleh ubah EK dalam kajian ini diukur dengan menggunakan soal selidik Teachers' Sense of Efficacy Scale (TSES) (Tschannen-Moran \& Hoy, 2001) yang telah diterjemahkan ke dalam bahasa Melayu. Instrumen asal terdiri daripada 12 item, selepas analisis faktor penerokaan (EFA) dijalankan tiga faktor dikekalkan tetapi satu item digugurkan kerana factor loading $<0.45$ dengan keseluruhan penjelasan varian adalah sebanyak 79.7\%. 11 item dengan skala Likert lima mata digunakan untuk mengukur tiga dimensi tersebut iaitu penglibatan murid (4 item), strategi pengajaran ( 3 item), dan pengurusan bilik darjah (4 item). Analisis faktor pengesahan (CFA) bagi tiga konstruk pemboleh ubah efikasi kendiri menunjukkan indeks kesepadanan yang baik $(R M S E A=0.77 ; G F I=0.94 ; C F I=0.97$; $T L I=0.96$ ). Nilai pekali Alpha Cronbach bagi ketiga-tiga dimensi ialah 0.88, 0.86, dan 0.93.

Instrumen Pengajaran Pendidikan Islam berintegrasikan KBAT dalam kajian ini diadaptasi daripada empat soal selidik kajian lepas (Azian Abdul Aziz @ Ahmad et al., 2017; Mohd Syaubari Othman, 2019; Sukiman Saad et al., 2012; Wan Amirah Wan Ismail et al., 2016). Instrumen asal terdiri daripada 34 item yang digunakan untuk mengukur tiga dimensi. Selepas analisis faktor penerokaan (EFA) dijalankan, empat faktor telah diekstrak dan sembilan item digugurkan kerana factor loading $<0.45$ dengan keseluruhan penjelasan varian adalah sebanyak $69.7 \%$. Seterusnya, analisis faktor pengesahan (CFA) bagi empat konstruk ini dijalankan, dua item telah digugurkan. Analisis faktor pengesahan sekali lagi dijalankan ke atas model yang telah dimodifikasi dan hasil menunjukkan indeks kesepadanan yang lebih baik $(R M S E A=0.60 ; G F I=0.90 ; C F I=0.95 ; T L I=0.94) .23$ item dikekalkan bagi mengukur empat dimensi iaitu perancangan pengajaran (6 item), penyampaian pengajaran (4 item), perkembangan pengajaran (9 item), dan penilaian pengajaran (4 item). Nilai pekali Alpha Cronbach bagi empat dimensi ialah 0.90, 0.90, 0.92, dan 0.85 .

\section{Analisis Data}

Dalam kajian ini, kepercayaan dikenal pasti sebagai pemboleh ubah yang berada di peringkat kumpulan (Bellibaş \& Gümüş, 2021; Çoban et al., 2020; Hoy \& Tschannen-Moran, 1999). Secara umumnya, guru-guru yang berada di sekolah yang sama akan berkongsi persepsi yang sama. Justeru, unit analisis bagi pemboleh ubah ini adalah sekolah bukannya individu guru. Oleh itu, analisis secara multilevel modeling dua aras menggunakan perisian HLM (hierarchical linear modeling) (Raudenbush \& Bryk, 2002) versi 8.0 digunakan untuk menguji hipotesis dalam kajian ini.

Model aras rendah (lower level) iaitu peringkat individu dibina untuk menganalisis hubungan antara EK dan pengajaran Pendidikan Islam berintegrasikan KBAT. Manakala model silang aras (cross-level) dibina untuk menganalisis hubungan antara kepercayaan yang berada pada aras tinggi (peringkat kumpulan) ke atas kesan pemboleh ubah yang berada pada aras rendah (peringkat individu). Seterusnya, bagi mengesahkan kewujudan kesan mediator iaitu EK, pengkaji menggunakan kaedah Monte Carlo bootstrapping (Preacher \& Selig, 2010) pada aras 95\% sela keyakinan dengan 20,000 kali pengulangan. Hipotesis kajian dan kesan mediator dijelaskan sebagaimana rajah 1 di bawah. 


\section{Rajah 1: Kesan Mediator Efikasi Kendiri}

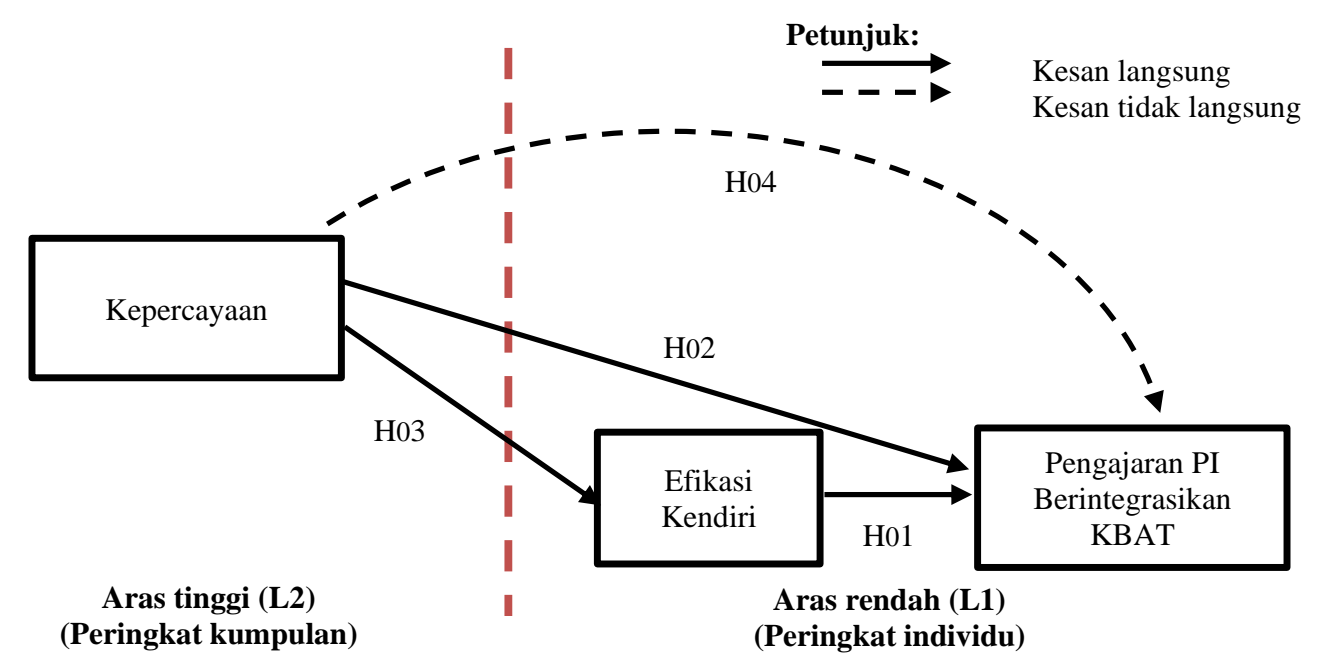

\section{Hasil Kajian}

Bagi menentukan kewajaran untuk menjalankan analisis secara multilevel modeling, beberapa prosedur telah dijalankan berdasarkan cadangan Mathieu dan Taylor (2007). Nilai min, sisihan piawai, korelasi, mean rwg, FIII, dan ICC (1) diringkaskan seperti dalam jadual 1. Keputusan analisis korelasi pearson bivariate menunjukkan terdapat hubungan yang signifikan antara pemboleh ubah peringkat individu (efikasi kendiri dan pengajaran PI berintegrasikan KBAT) $r=.735, p<.01$. Nilai mean rwg bagi pemboleh ubah kepercayaan $=.98$, melebihi .70 menunjukkan tahap persetujuan yang mencukupi untuk pengagregatan (Chen et al., 2004). Nilai FIII bagi pemboleh ubah kepercayaan $=1.67, p<.001$ adalah signifikan. Seterusnya, nilai ICC (1) bagi pemboleh ubah kepercayaan $=.10$ iaitu antara .05 hingga .20 adalah diterima untuk prosedur agregat (Bliese, 2000; Peugh, 2010).

Jadual 1: Analisis deskriptif dan korelasi

\begin{tabular}{lllllllll}
\hline Pemboleh Ubah & M & S. P & $\mathbf{1}$ & $\mathbf{2}$ & $\mathbf{3}$ & $\begin{array}{l}\text { Mean } \\
\text { rwg }\end{array}$ & FIII & $\begin{array}{l}\text { ICC } \\
(\mathbf{1})\end{array}$ \\
\hline 1. Kepercayaan & 4.17 & .460 & 1 & & & .98 & $1.67^{* * * *}$ & .10 \\
2. EK & 4.16 & .487 & $.590^{* *}$ & 1 & & & & \\
3. Pengajaran KBAT & 4.10 & .476 & $.530^{* *}$ & $.735^{* *}$ & 1 & & & \\
\hline
\end{tabular}

Nota: $N=642$ individu, 112 kumpulan

$* * p<.01, * * * p<.001$

Jadual 2: Analisis HLM

\begin{tabular}{lllll}
\hline Kesan & $\begin{array}{l}\text { Pengajaran } \\
\text { KBAT }\end{array}$ & $\begin{array}{l}\text { Pengajaran } \\
\text { KBAT }\end{array}$ & $\begin{array}{l}\text { Efikasi } \\
\text { Kendiri }\end{array}$ & $\begin{array}{l}\text { Pengajaran } \\
\text { KBAT }\end{array}$ \\
\cline { 2 - 5 } Model & $\mathbf{1}$ & $\mathbf{2}$ & $\mathbf{3}$ & $\mathbf{4}$ \\
\hline $\begin{array}{l}\text { Kesan aras rendah } \\
\text { Efikasi Kendiri }\end{array}$ & $0.73(0.02) * * *$ & & & $0.73(0.02) * * *$ \\
\hline $\begin{array}{l}\text { Kesan silang aras } \\
\text { Kepercayaan }\end{array}$ & & $0.20(0.03) * * *$ & $0.26(0.03) * * *$ & $0.01(0.03) n s$ \\
\hline
\end{tabular}

Nota: $N=642$ individu, 112 kumpulan

$* * * p<.001$

Nilai pertama ialah anggaran parameter dan nilai dalam kurungan ialah sisihan piawai. 
Bagi analisis aras rendah, efikasi kendiri dimasukkan ke dalam model analisis HLM untuk melihat kesannya ke atas pengajaran Pendidikan Islam berintegrasikan KBAT. Sebagaimana yang ditunjukkan dalam Model 1 dalam jadual 2, keputusan menunjukkan hubungan efikasi kendiri ke atas pengajaran Pendidikan Islam berintegrasikan KBAT adalah signifikan $(\beta=0.73, S E=0.02, p<.001)$, maka H01 adalah ditolak. Seterusnya, bagi analisis silang aras iaitu melihat kesan kepercayaan yang berada pada peringkat kumpulan ke atas kesan pemboleh ubah yang berada pada peringkat individu, analisis model 2 dalam jadual 2, menunjukkan hubungan kepercayaan ke atas pengajaran Pendidikan Islam berintegrasikan KBAT adalah signifikan $(\gamma=0.20, S E=0.03, p<.001)$, maka H02 adalah ditolak. Manakala, analisis model 3 menunjukkan hubungan kepercayaan ke atas efikasi kendiri adalah signifikan $(\gamma=.26, S E=0.03, p<.001)$, maka $\mathrm{H} 03$ adalah ditolak.

Tiga syarat yang digariskan oleh Baron \& Kenny (1986) perlu dipenuhi bagi menguji kesan mediator. Syarat pertama berdasarkan model 2, kepercayaan yang berada di peringkat kumpulan berhubung secara positif dan signifikan dengan pengajaran Pendidikan Islam berintegrasikan KBAT yang berada di peringkat individu $(\gamma=0.20, S E=0.03, p<.001)$. Manakala syarat kedua, model 3 menunjukkan kepercayaan yang berada di peringkat kumpulan berhubung secara positif dan signifikan dengan efikasi kendiri yang berada di peringkat individu $(\gamma=.26, S E=0.03, p<.001)$. Seterusnya syarat ketiga, model 4 menunjukkan efikasi kendiri GPI yang berada di peringkat individu berhubung secara positif dan signifikan dengan pengajaran Pendidikan Islam berintegrasikan KBAT yang berada di peringkat yang sama $(\gamma=.73, S E=0.02, p<.001)$.

Pengkaji menggunakan kaedah Monte Carlo bootstrapping (Preacher \& Selig, 2010) bagi mengesahkan kewujudan kesan mediator. Nilai signifikan mediator ialah apabila nilai lower level (LL) dan upper level (UL) tidak mengandungi nilai sifar (not content zero) (MacKinnon et al., 2004). Berdasarkan dapatan daripada ujian Monte Carlo bootstrapping seperti dalam rajah 2 yang dijalankan di laman web http://www.quantpsy.org/medmc/medmc.htm, di dapati nilai lower level $=0.14$ dan upper level $=0.23$ adalah positif dan tidak mengandungi nilai sifar. Keputusan ini membuktikan bahawa pemboleh ubah efikasi kendiri berperanan sebagai mediator terhadap hubungan antara pemboleh ubah kepercayaan pada peringkat kumpulan dengan pengajaran Pendidikan Islam berintegrasikan KBAT pada peringkat individu, maka H04 adalah ditolak.

\section{Rajah 2: Histogram Monte Carlo bootstrapping}

\section{Distribution of Indirect Effect}

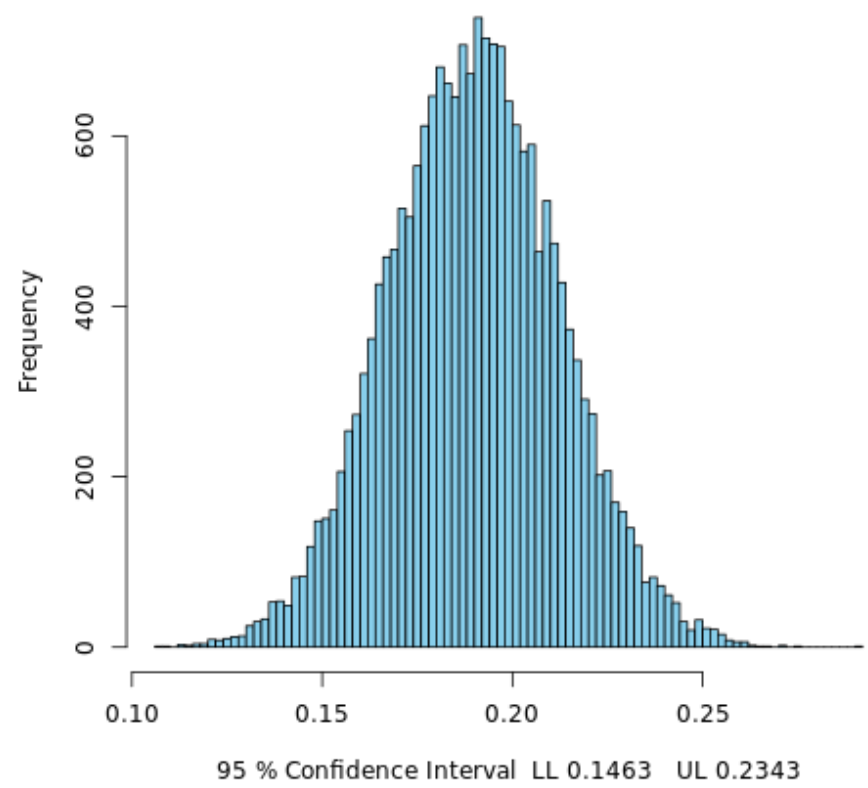




\section{Perbincangan dan Implikasi Kajian}

Pengajaran KBAT merentas kurikulum kini menjadi matlamat kebanyakan polisi pendidikan di seluruh dunia (Zohar \& Alboher Agmon, 2017). Malaysia juga sedang berusaha menuju ke arah pengintegrasian KBAT secara menyeluruh dalam kurikulum dan amalan pengajaran guru. Usaha ini bermula apabila keputusan TIMSS 2011 dan PISA 2009 menunjukkan murid Malaysia tidak mencapai prestasi yang baik dalam kemahiran kognitif seperti mengaplikasikan pengetahuan dan menaakul dalam penyelesaian masalah (Kementerian Pendidikan Malaysia, 2013). Walaupun pengintegrasian KBAT dalam amalan pengajaran telah mula ditekankan dalam kurikulum di Malaysia sejak tahun 2013 lagi (Kementerian Pendidikan Malaysia, 2018), namun beberapa faktor kelemahan untuk mengintegrasikan KBAT dalam amalan pengajaran telah dikenal pasti seperti faktor kurangnya kepercayaan guru terhadap keupayaan murid dan persepsi negatif terhadap elemen KBAT (Abdul Talib Hashim et al., 2015; Onosko, 1991; Zohar et al., 2001; Zohar \& Schwartzer, 2005), serta kurangnya keyakinan guru dalam mengintegrasikan KBAT (Mohamad Zaid Mustafa et al., 2018; Nur Hawa Hanis Abdullah \& Ghazali Darusalam, 2018).

Berdasarkan faktor tersebut, dapatan kajian ini memberikan bukti secara empirikal bahawa persepsi guru terhadap keupayaan murid dan elemen KBAT dapat diubah dengan wujudnya kepercayaan dalam komuniti di sekolah. Kepercayaan merupakan faktor persekitaran yang dapat membantu dalam penambahbaikan sekolah (Forsyth et al., 2006; Tschannen-Moran \& Hoy, 1998). Kajian-kajian empirikal menunjukkan persekitaran sekolah yang mempunyai nilai kepercayaan yang tinggi memberi kesan kepada amalan dan prestasi pengajaran guru (Happy Fitria, 2018; Liou et al., 2016) serta memberi motivasi kepada guru untuk berinovasi (Cai \& Tang, 2021). Selain itu, kajian ini berjaya membuktikan wujudnya kesan pengaruh pemboleh ubah yang berada pada aras tinggi (upper level) ke atas pemboleh ubah yang berada pada aras rendah (lower level) apabila diuji secara serentak menggunakan pendekatan multilevel modeling. Dengan kata lain, dapatan kajian ini telah memberi sumbangan literatur yang baharu kepada bidang pendidikan melalui pendekatan multilevel seperti yang dicadangkan oleh Liu dan Hallinger (2018); Zheng et al. (2020). Pendekatan multilevel adalah ujian yang paling tepat digunakan untuk menjawab persoalan kajian ini kerana sifat data yang pelbagai aras dan melibatkan sampel kajian berkelompok (clustered) (Maele \& Houtte, 2014).Walaupun jelas bahawa kepercayaan bersifat dengan ciri-ciri multilevel, namun kajian-kajian empirikal tentang kepercayaan serta hasilnya secara multilevel adalah terhad khususnya di Malaysia.

Seterusnya, dapatan kajian ini memberikan bukti secara empirikal bahawa kepercayaan dapat menjadi faktor persekitaran yang berpotensi menjadi sumber untuk meningkatkan EK guru. Sebagaimana yang diperjelaskan oleh Bandura (1997) bahawa EK dapat dibentuk melalui persekitaran yang sesuai seterusnya menghasilkan tingkah laku yang sewajarnya. Faktor persekitaran dapat meningkatkan EK melalui keempat-empat sumber iaitu pengalaman penguasaan, pengalaman pemerhatian, pujukan verbal, dan juga rangsangan psikologi dan emosi. Kepercayaan dalam kalangan komuniti di sekolah dapat meningkatkan EK apabila guru percaya dan saling bergantung kepada kompetensi dan kemahiran pentadbir, rakan sekerja, murid dan ibu bapa (pengalaman pemerhatian). Kepercayaan melalui elemen kompetensi menjadikan individu yang diperhatikan lebih yakin dan melakukan sesuatu tindakan mengikut standard yang sepatutnya (Hoy et al., 2006). Manakala rasa kebolehpercayaan, kejujuran, dan keterbukaan daripada maklum balas, perbincangan, dan galakan yang diterima daripada pengalaman mengajar (pujukan verbal dan rangsangan psikologi dan emosi), boleh menjadikan guru bertingkah laku lebih positif dan bertindak yang terbaik untuk diri dan orang lain (Hoy et al., 2006).

Dapatan kajian ini juga menyokong dapatan kajian-kajian lepas bahawa guru yang berefikasi tinggi bersikap lebih positif terhadap dirinya, muridnya, dan sesuatu amalan pengajaran yang baru (Zheng et al., 2020), mengurangkan tekanan guru dalam menghadapi perubahan kurikulum (Putwain \& Embse, 2018); menjadi peramal terkuat terhadap komitmen guru dalam pengajaran, serta menggalakkan pengajaran KBAT di bilik darjah (Davies, 2004). Guru yang mempunyai tahap EK yang tinggi juga mampu bertoleransi terhadap salah laku murid (Gholami et al., 2016); mempunyai keyakinan yang tinggi untuk mengubah pengajaran dan strategi penilaian untuk disesuaikan dengan murid serta cenderung mempraktikkan amalan pengajaran yang memfokuskan peningkatan prestasi murid (Wolters \& Daugherty, 2007). 
Dapatan kajian ini menyokong dan menyumbang kepada pengembangan Teori Kognitif Sosial (Bandura, 1986) dengan menekankan bahawa tindakan manusia beroperasi dalam struktur yang saling bergantungan yang melibatkan hubungan timbal balik triad (triad reciprocal), serta terdiri daripada faktor personal (kognitif, afektif, dan keadaan biologi), tingkah laku, dan faktor persekitaran. Ketigatiga faktor ini saling berinteraksi dan mempengaruhi antara satu sama lain melalui dua arah. Dalam kajian ini, kepercayaan bertindak sebagai faktor persekitaran yang mempengaruhi faktor personal iaitu efikasi kendiri, seterusnya mempengaruhi tingkah laku guru iaitu amalan pengajaran Pendidikan Islam berintegrasikan KBAT. Selain itu, Teori Kognitif Sosial ini juga menekankan kepentingan faktor personal yang memberi pengaruh terbesar dalam tindakan manusia (Bandura, 2002). Dalam kajian ini, faktor personal iaitu efikasi kendiri juga berperanan sebagai mediator kerana dilihat lebih dominan dengan mempengaruhi kekuatan hubungan antara pemboleh ubah bebas dan bersandar (Baron \& Kenny, 1986; Preacher \& Selig, 2012). Walaupun terdapat beberapa kajian empirikal yang telah menyumbang kepada pemahaman hubungan antara faktor persekitaran, faktor personal, dan tingkah laku (Aziah Ismail et al., 2015; Goddard \& Goddard, 2001; Hsu et al., 2007; Lakshmanan et al., 2011; Le, 2013; Schunk, 2003), namun, lebih banyak kajian lanjutan perlu dilakukan untuk menjelaskan hubungan antara mediator efikasi kendiri yang wujud dalam konteks pendidikan, dan bagaimana kesannya kepada tingkah laku guru (Schipper et al., 2019).

Kajian ini memberi implikasi dalam aspek praktikal di sekolah. Dapatan kajian ini menjelaskan bahawa faktor personal iaitu efikasi kendiri adalah pendorong utama kepada tingkah laku guru Pendidikan Islam untuk mempraktikkan pengajaran berintegrasikan KBAT. Justeru, faktor-faktor yang dapat meningkatkan efikasi kendiri guru perlu menjadi fokus oleh pihak pentadbir di sekolah. Untuk meningkatkan efikasi kendiri dalam kalangan guru dengan lebih efektif, pihak pentadbir perlu fokus kepada empat sumber seperti yang dijelaskan oleh Bandura (1997) iaitu pengalaman penguasaan, pengalaman pemerhatian, pujukan verbal, dan rangsangan psikologi dan emosi. Keempat-empat sumber ini dapat diwujudkan melalui faktor persekitaran iaitu kepercayaan dalam komuniti di sekolah.

\section{Kesimpulan}

Hasil dapatan kajian ini menunjukkan kepercayaan dan EK mempengaruhi pengajaran Pendidikan Islam berintegrasikan KBAT. Malah, EK juga berperanan sebagai mediator antara hubungan kepercayaan dan pengajaran Pendidikan Islam berintegrasikan KBAT. Kepercayaan juga dilihat sebagai faktor persekitaran yang efektif untuk meningkatkan tahap EK GPI. Oleh itu, dalam situasi pandemik Covid-19 ini, persekitaran komuniti yang saling percaya dilihat menjadi medium yang menyokong GPI untuk saling bergantung kepada kompetensi dan kemahiran komuniti di sekolah serta mengubah persepsi dan sikap GPI dalam aspek teknologi dan aplikasi digital demi mendepani cabaran dalam melaksanakan pengajaran dan pembelajaran di rumah (PdPr). Lebih-lebih lagi dapatan kajian menunjukkan kemahiran dan sikap GPI terhadap PdP atas talian berada pada tahap sederhana (Nurul Farhana Rerah \& Mohd Faisal Mohamed, 2021). Kewujudan persekitaran yang saling mempercayai dalam komuniti sekolah menjadikan guru-guru lebih terbuka untuk berkongsi idea, berkolaborasi, sanggup berkongsi amalan pengajaran dengan rakan-rakan, mengurangkan konflik dalam komuniti di sekolah, serta dapat membentuk iklim sekolah yang positif (Bryk \& Schneider, 2003). Manakala, EK juga dilihat sebagai pemboleh ubah penting yang menjadi motivasi dan pendorong kepada guru untuk melaksanakan PdPr secara lebih efektif. EK yang tinggi dapat mengurangkan tekanan guru (Gholami et al., 2016; Putwain \& Embse, 2018; Zee \& Koomen, 2016) untuk menghadapi perubahan kurikulum dan mengadaptasi amalan PdPr yang menjadi norma baharu dalam sistem pendidikan di Malaysia mahupun dunia.

\section{Rujukan}

Abdul Talib Hashim, Rosma Osman, Azli Arifin, Norazilawati Abdullah, \& Noh, N. M. (2015). Teachers' perception on higher order thinking skills as an innovation and its implementation in History teaching. Australian Journal of Basic and Applied Sciences, 9(32), 215-221.

Absha Atiah Abu Bakar, \& Mohd Isa Hamzah. (2019). Professional learning community practices in 
improving self-efficacy of elementary school Islamic education teachers at Melaka Tengah, Melaka. International Journal of Education and Pedagogy, 1(1), 37-49.

Al- Ghazali. Terj. Ismail Yakub. (1988). Ihya' Ulumuddin. Pustaka Nasional Pte Ltd.

Ashton, P. (1984). Teacher Efficacy: A Motivational Paradigm for effective teacher education. Journal of Teacher Education, XXXV(5), 28-32. https://doi.org/10.1007/978-0-387-71799-9_418

Aziah Ismail, Loh, H. Y., \& Abdul Ghani Kanesan Abdullah. (2015). Komuniti pembelajaran profesional dan efikasi kendiri guru sekolah menengah di Pulau Pinang. Jurnal Kepimpinan Pendidikan, 2(1), 1-12.

Azian Abdul Aziz @ Ahmad, Fauziah Ismail, Noor Mala Ibrahim, \& Norhanim Abdul Samat. (2017). Investigating the implementation of higher order thinking skills in Malaysian classrooms: Insights from L2 teaching practices. Sains Humanika, 9(4-2), 65-73. https://doi.org/10.11113/sh.v9n42.1361

Bahagian Pembangunan Kurikulum. (2015). Dokumen Standard Kurikulum dan Pentaksiran Pendidikan Islam. Kementerian Pendidikan Malaysia.

Bandura, A. (1977). Self-efficay: Toward a unifying theory a behavioral change. Psychological Review, 84(2), 191-215. https://doi.org/10.1007/978-3-319-75361-4

Bandura, A. (1986). Social foundations of thoughts and action: A social cognitive theory. PrenticeHall.

Bandura, A. (1997). Self-efficacy: The exercise of control. W.H. Freeman and Company.

Bandura, A. (2002). Social cognitive theory in cultural context. Applied Psychology: An International Review, 51(2), 269-290. https://doi.org/10.1111/1464-0597.00092

Baron, R. M., \& Kenny, D. A. (1986). The Moderator-Mediator Variable Distinction in Social Psychological Research. Conceptual, Strategic, and Statistical Considerations. Journal of Personality and Social Psychology, 51(6), 1173-1182. https://doi.org/10.1037/00223514.51.6.1173

Bellibaş, M. Ş., \& Gümüş, S. (2021). The Effect of Learning-Centred Leadership and Teacher Trust on Teacher Professional Learning: Evidence from a Centralised Education System. Professional Development in Education, 00(00), 1-13. https://doi.org/10.1080/19415257.2021.1879234

Bliese, P. D. (2000). Within-group agreement, non-independence, and reliability: Implications for data aggregation and analysis. In K. J. Klein \& S. W. J. Kozlowski (Eds.), Multilevel theory, research, and methods in organizations: Foundations, extensions, and new directions (pp. 349-381). San Francisco: Jossey-Bass.

Bryk, A. S., \& Schneider, B. (2003). Trust in schools: A core resource for school reform. Educational Leadership, 60(6), 40-44.

Cai, Y., \& Tang, R. (2021). School support for teacher innovation: Mediating effects of teacher selfefficacy and moderating effects of trust. Thinking Skills and Creativity, 41(May), 1-15. https://doi.org/10.1016/j.tsc.2021.100854

Chan, W. Y., Lau, S., Nie, Y., Lim, S., \& Hogan, D. (2008). Organizational and personal predictors of teacher commitment: The mediating role of teacher efficacy and identification with school. American Educational Research Journal, 45(3), 597-630. https://doi.org/10.3102/0002831208318259

Chen, G., Mathieu, J. E., \& Bliese, P. D. (2004). A Framework for Conducting Multi-Level Construct Validation. Research in Multi-Level Issues, 3, 273-303. https://doi.org/10.1016/S14759144(04)03013-9

Choong Yuen Onn, Jamal Nordin Yunus, Hamidah Yusof, Krishna Moorthy, \& Seow Ai Na. (2018). The mediating effect of trust on the dimensionality of organisational justice and organisational citizenship behaviour amongst teachers in Malaysia. Educational Psychology, 38(8), 1010-1031. https://doi.org/10.1080/01443410.2018.1426836

Çoban, Ö., Özdemir, N., \& Bellibaş, M. Ş. (2020). Trust in principals, leaders' focus on instruction, teacher collaboration, and teacher self-efficacy: testing a multilevel mediation model. Educational Management Administration and Leadership, 1-21. https://doi.org/10.1177/1741143220968170

Cohen, L., Manion, L., \& Morrison, K. (2018). Research Methods in Education. In Routledge Tylor \& Francis Group (Eighth Edi). Routledge Tylor \& Francis Group.

Creswell, J. W. (2012). Educational Research: Planning, Conducting and Evaluating Quantitative and Qualitative Research (Fourth Edi). Pearson Education. 
Dale, R. L. (2004). The effect of teacher collaboration and school trust on collective efficacy! Dissertation of Doctor Of Education, Oklahoma State University.

Davies, B. (2004). The relationship between teacher efficacy and higher order instructional emphasis. In In Annual Meeting of the Australian Association for Research in Education.

Forsyth, P. B., Barnes, L. L. B., \& Adams, C. M. (2006). Trust-effectiveness patterns in schools. Journal of Educational Administration, 44(2), 122-141. https://doi.org/10.1108/09578230610652024

Gholami, M., Moghadam, P. K., Mohammadipoor, F., Tarahi, M. J., Sak, M., Toulabi, T., \& Pour, A. H. H. (2016). Comparing the effects of problem-based learning and the traditional lecture method on critical thinking skills and metacognitive awareness in nursing students in a critical care nursing course. Nurse Education Today, 45, 16-21. https://doi.org/10.1016/j.nedt.2016.06.007

Goddard, R. D., \& Goddard, Y. L. (2001). A multilevel analysis of the relationship between teacher and collective efficacy in urban schools. Teaching and Teacher Education, 17(7), 807-818. https://doi.org/10.1016/S0742-051X(01)00032-4

Goddard, R. D., Hoy, W. K., \& Hoy, A. W. (2004). Collective efficacy beliefs:Theoretical developments, empirical evidence, and future directions. Educational Researcher, 33(3), 3-13. https://doi.org/10.3102/0013189X033003003

Goddard, R. D., Hoy, W. K., \& Woolfolk Hoy, A. (2000). Collective teacher efficacy: Its meaning, measure, and impact on student achievement. American Educational Research Journal, 37(2), 479-507. https://doi.org/10.3102/00028312037002479

Goddard, R. D., Skrla, L., Salloum, S. J., Goddard, R. D., Skrla, L., Salloum, S. J., \& Role, T. (2017). The Role of Collective Efficacy in Closing Student Achievement Gaps : A Mixed Methods Study of School Leadership for Excellence and Equity The Role of Collective Ef fi cacy in Closing Student Achievement. Journal of Education for Students Placed at Risk, November, 1-18. https://doi.org/10.1080/10824669.2017.1348900

Gray, J. (2016). Investigating the role of collective trust, collective efficacy, and enabling school structures on overall school effectiveness. Education Leadership Review, 17(1), 114-128.

Happy Fitria. (2018). The influence of organizational culture and trust through the teacher performance in the private secondary school in Palembang. International Journal of Scientific and Technology Research, 7(7), 82-86.

Haswani Dzul. (2017). Aplikasi elemen kemahiran berfikir aras tinggi (KBAT) dalam pengajaran Pendidikan Islam sekolah rendah. (Disertasi sarjana yang tidak diterbitkan). Universiti Malaya, Kuala Lumpur, Malaysia.

Hoy, W. K., Gage, C. Q., \& Tarter, C. J. (2006). School mindfulness and faculty trust: Necessary conditions for each other? Educational Administration Quarterly, 42(2), 236-255. https://doi.org/10.1177/0013161X04273844

Hoy, W. K., \& Tschannen-Moran, M. (1999). Five faces of trust: An empirical confirmation in urban elementary schools. Journal of School Leadership, 9(3), 184-208. https://doi.org/10.1177/105268469900900301

Hoy, W., \& Tschannen-Moran, M. (2003). Omnibus T-Scale. 181-208.

Hsu, M. H., Ju, T. L., Yen, C. H., \& Chang, C. M. (2007). Knowledge sharing behavior in virtual communities: The relationship between trust, self-efficacy, and outcome expectations. International Journal of Human Computer Studies, 65(2), 153-169. https://doi.org/10.1016/j.ijhcs.2006.09.003

Jumadi Musa, Mohamad Nizam Nazarudin, Zakiah Noordin, Nur Afny Juati, \& Hujaimah @ Siti Syafiqah Juhumin. (2020). Investigating Instructional Leadership, Transformational Leadership, Self-Efficacy and Trust Among Primary School Teacher. International Journal of Education, Psychology and Counseling, 5(35), 237-248. https://doi.org/10.35631/ijepc.5350021

Kamarul Azmi Jasmi. (2010). Guru cemerlang Pendidikan Islam sekolah menengah di Malaysia: Satu kajian kes. (Tesis Doktor Falsafah yang tidak diterbitkan). Universiti Kebangsaan Malaysia, Bangi, Malaysia.

Kementerian Pendidikan Malaysia. (2013). Pelan Pembangunan Pendidikan Malaysia 2013-2025 (Pendidikan Prasekolah hingga Lepas Menengah).

Kementerian Pendidikan Malaysia. (2018). Laporan Tahunan 2017 Pelan Pembangunan Pendidikan Malaysia 2013-2025. https://www.padu.edu.my/wp-content/uploads/2018/07/PADU-LAPORANTAHUNAN-BM-2017-1.pdf 
Klassen, R. M., \& Tze, V. M. C. (2014). Teachers' self-efficacy, personality, and teaching effectiveness: A meta-analysis. Educational Research Review, 12, 59-76. https://doi.org/10.1016/j.edurev.2014.06.001

Klassen, R. M., Tze, V. M. C., Betts, S. M., \& Gordon, K. A. (2011). Teacher efficacy research 19982009: Signs of progress or unfulfilled promise? Educational Psychology Review, 23(1), 21-43. https://doi.org/10.1007/s10648-010-9141-8

Lakshmanan, A., Heath, B. P., Perlmutter, A., \& Elder, M. (2011). The impact of science content and professional learning communities on science teaching efficacy and standards-based instruction. Journal of Research in Science Teaching, 48(5), 534-551. https://doi.org/10.1002/tea.20404

Le, L. K. (2013). Teacher-efficacy for using HOTS pedagogy in the classroom [(Master's theses). University of Connecticut]. http://digitalcommons.uconn.edu/gs_theses/406

Lee, J. C. K., Zhang, Z., \& Yin, H. (2011). A multilevel analysis of the impact of a professional learning community, faculty trust in colleagues and collective efficacy on teacher commitment to students. Teaching and Teacher Education, 27(5), 820-830. https://doi.org/10.1016/j.tate.2011.01.006

Ling Ying Leh. (2016). Pengaruh Persekitaran Maklum Balas, Kepercayaan Terhadap Pemimpin dan Komunikasi Bimbingan Terhadap Efikasi Kendiri Pengajaran di Politeknik Malaysia. (Tesis Doktor Falsafah yang tidak diterbitkan). Universiti Sains Malaysia.

Liou, Y. H., Daly, A. J., Canrinus, E. T., Forbes, C. A., Moolenaar, N. M., Cornelissen, F., Van Lare, M., \& Hsiao, J. (2016). Mapping the social side of pre-service teachers: connecting closeness, trust, and efficacy with performance. Teachers and Teaching: Theory and Practice, 23(6), 635657. https://doi.org/10.1080/13540602.2016.1218329

Liu, S., \& Hallinger, P. (2018). Principal Instructional Leadership, Teacher Self-Efficacy , and Teacher Professional Learning in China: Testing a Mediated-Effects Model. Educational Administration Quarterly, 1-28. https://doi.org/10.1177/0013161X18769048

MacKinnon, D. P., Lockwood, C. M., \& Williams, J. (2004). Confidence limits for the indirect effect: Distribution of the product and resampling methods. Multivariate Behavioral Research, 39(1), 99-128. https://doi.org/10.1207/s15327906mbr3901_4

Maele, D. Van, \& Houtte, M. Van. (2014). Teacher Trust in Students and the Organizational School Context: The Role of Student Culture and Teachability Perceptions. In D. Van Maele, P. B. Forsyth, \& M. Van Houtte (Eds.), Trust and School Life: The Role of Trust for Learning, Teaching, Leading, and Bridging (pp. 171-188). Springer.

Mathieu, J. E., \& Taylor, S. R. (2007). A framework of testing meso-mediational relationships in Organizational Behavior. Journal of Organizational Behavior, 28, 141-172. https://doi.org/10.1002/job

Megan Tschannen-Moran, A. W. H. and W. K. . H. (1998). Teacher efficacy: Its meaning and measure. Review of Educational Research, 68(2), 202-248.

Mohamad Zaid Mustafa, Mohd Sa'ari Mohd Salleh, Rosnee Ahad, \& Abdul Rasid Abdul Razzaq. (2018). Kemahiran berfikir aras tinggi (KBAT) dalam kalangan guru Pendidikan Islam sekolah menengah kebangsaan daerah Batu Pahat, Johor. Human Sustainability Procedia (INSAN 2018 EProceeding), 9-17.

Mohamad Zaidir Zainal Abidin, \& Kamisah Osman. (2017). Tahap pengetahuan, pemahaman, kemahiran, dan pelaksaanaan guru sains terhadap kemahiran berfikir aras tinggi ( KBAT ). Journal of Advanced Research in Social and Behavioural, 8(1), 97-113.

Mohd Syaubari Othman. (2019). Pelaksanaan Komposisi Pengajaran Guru Pendidikan Islam yang Megintegrasikan Kemahiran Berfikir Aras Tinggi (KBAT) Dalam Bidang Akidah Sekolah Rendah Malaysia. (Tesis Ijazah Doktor Falsafah). Tanjong Malim: Universiti Pendidikan Sultan Idris.

Mohd Zaidi Mohd Zeki, Noor Muslieh Mustafa Kamal, Riyan Hidayat, Nurul Hijja Mazlan, \& Nurulaini Moshidi. (2021). Cadangan Penyelesaian Pakar Pendidikan Berkaitan Pengajaran Guru Pendidikan Islam dalam Mengintegrasikan Kemahiran Berfikir Aras Tinggi di Sekolah Menengah. Journal of Islamic Educational Research, 6, 18-34.

Noornajihan Jaafar. (2014). Pengaruh efikasi kendiri dan faktor persekitaran terhadap kualiti Guru Pendidikan Islam sekolah menengah kebangsaan. (Tesis Doktor Falsafah yang tidak diterbitkan). Universiti Kebangsaan Malaysia, Bangi, Malaysia.

Noornajihan Jaafar, \& Ab Halim Tamuri. (2013). Hubungan antara efikasi kendiri dengan kualiti guru Pendidikan Islam sekolah menengah kebangsaan Malaysia. Journal of Islamic and Arabic 
Education, 5(1), 41-60.

Norasmahani Nor, Nur Sofiah Suhaimi, Nur Syamira Abdul Wahab, Mohd Khushairi Che Ismail, Mohd Aderi Che Noh, \& Khadijah Abdul Razak. (2015). Pelaksanaan KBAT dalam pengajaran dan pembelajaran Pendidikan Islam sekolah menengah: Satu tinjauan di Putrajaya. Proceeding: 7th International Seminar on Regional Education, 361-375.

Nur Hawa Hanis Abdullah, \& Ghazali Darusalam. (2018). Kesediaan guru melaksanakan kemahiran berfikir aras tinggi dalam pengajaran. Jurnal Kurikulum \& Pengajaran Asia Pasifik, 6(3), 22-31.

Nursafra Mohd Zhaffar. (2017). Kefahaman dan amalan penerapan pemikiran kritis dalam pengajaran Pendidikan Islam sekolah menengah. (Tesis Doktor Falsafah yang tidak diterbitkan). Universiti Kebangsaan Malaysia, Bangi, Malaysia.

Nurul Farhana Rerah, \& Mohd Faisal Mohamed. (2021). Tahap Pengetahuan, Kemahiran dan Sikap Guru Pendidikan Islam (GPI) Terhadap Kesediaan Pengajaran dan Pembelajaran (PdP) Mod Atas Talian. Malaysian Journal of Social Sciences and Humanities (MJSSH), 6(10), 82-89. https://doi.org/10.47405/mjssh.v6i10.1076

Okpogba, D. (2001). Organizational structure, collegial trust, and college faculty teaching efficacy: A case study [Dissertation of Doctor Of Education, Oklahoma State University]. https://doi.org/10.1021/ja003690f

Onosko, J. J. (1991). Barriers to the Promotion of Higher-Order Thinking in Social Studies. Theory and Research in Social Education, 19(4), 341-366. https://doi.org/10.1080/00933104.1991.10505646

Paxton, C. L. C., Leis, M., \& Rimm-Kaufman, S. E. (2014). Collective efficacy and adult community: Teacher and principal perceptions after two years of implementing "Leading Together" in schools. Society for Research on Educational Effectiveness.

Peugh, J. L. (2010). A practical guide to multilevel modeling. Journal of School Psychology, 48, 85112. https://doi.org/10.1016/j.jsp.2009.09.002

Preacher, K. J., \& Selig, J. P. (2010). Monte Carlo method for assessing multilevel Mediation: An interactive tool for creating confidence intervals for indirect effects in 1-1-1 multilevel models [Computer software]. http://quantpsy.org/

Preacher, K. J., \& Selig, J. P. (2012). Advantages of Monte Carlo Confidence Intervals for Indirect Effects. Communication Methods and Measures, 6(2), 77-98. https://doi.org/10.1080/19312458.2012.679848

Putwain, D. W., \& Embse, N. P. Von Der. (2018). Teacher self-efficacy moderates the relations between imposed pressure from imposed curriculum changes and teacher stress. Educational Psychology, O(0), 1-14. https://doi.org/10.1080/01443410.2018.1500681

Raudenbush, S. W., \& Bryk, A. S. (2002). Hierarchical Linear Models: Applications and Data Analysis Methods (Second Edi). Sage Publication, Inc.

Schipper, T. M., de Vries, S., Goei, S. L., \& van Veen, K. (2019). Promoting a professional school culture through lesson study? An examination of school culture, school conditions, and teacher self-efficacy. Professional Development in Education, 46(1), 1-18. https://doi.org/10.1080/19415257.2019.1634627

Schunk, D. H. (2003). Self-efficacy for reading and writing: Influence of modeling, goal setting, and self-evaluation. Reading and Writing Quarterly, 19(2), 159-172. https://doi.org/10.1080/10573560308219

Shamilati Che Seman, Wan Mazwati Wan Yusoff, \& Rahimah Embong. (2017). Teachers challenges in teaching and learning for higher order thinking skills (HOTS) in primary school. International $\begin{array}{llll}\text { Journal of Asian Social } & \text { Science, }\end{array}$ https://doi.org/10.18488/journal.1.2017.77.534.545

Sukiman Saad, Noor Shah Saad, \& Mohd Uzi Dollah. (2012). Pengajaran kemahiran berfikir: Persepsi dan amalan guru Matematik semasa pengajaran dan pembelajaran di bilik darjah. Jurnal Pendidikan Sains \& Matematik Malaysia, 2(1), 18-36.

Sukserm, T., \& Takahashi, Y. (2012). Self $\square$ efficacy as a mediator of the relationships between learning and ethical behavior from human resource development in corporate social responsibility activity. Asia-Pacific Journal of Business Administration, 4(1), 8-22. https://doi.org/10.1108/17574321211207944

Tschannen-Moran, M. (2004). What's trust got to do with it? The role of faculty and principal trust in fostering student achievement. In D. C.Thompson \& F. E. Crampton (Eds.), UCEA Conference 
Proceedings for Convention 2004. https://www.researchgate.net/publication/267851381

Tschannen-Moran, M., \& Hoy, A. W. (2001). Teacher efficacy: Capturing an elusive construct. Teaching and Teacher Education, 17(7), 783-805. https://doi.org/10.1016/S0742051X(01)00036-1

Tschannen-Moran, M., \& Hoy, W. (1998). Trust in schools: A conceptual and empirical analysis.

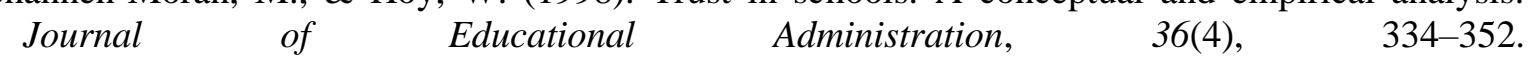
https://doi.org/10.1108/09578239810211518

Wahlstrom, K. L., \& Louis, K. S. (2008). How teachers experience principal leadership: The roles of professional community, trust, efficacy, and shared responsibility. Educational Administration Quarterly, 44(4), 458-495. https://doi.org/10.1177/0013161X08321502

Wan Ali Akbar Wan Abdullah, Nursafra Mohd Zhaffar, \& Ab. Halim Tamuri. (2020). Aplikasi Kemahiran Berfikir Aras Tinggi (KBAT) dalam Pendidikan Islam Mengikut Bidang. Sains Insani, 5(1), 14-21. https://doi.org/10.33102/sainsinsani.vol5no1.123

Wan Amirah Wan Ismail, Mohd Isa Hamzah, \& Maimun Aqsha Lubis. (2016). Kesediaan guru Pendidikan Islam sekolah rendah di Selangor terhadap penerapan KBAT dalam pengajaran dan pembelajaran. Journal of Advanced Research in Applied Sciences and Engineering Technology, 3(1), 79-92.

Wan Mat Sulaiman. (2011). Aplikasi kemahiran berfikir dalam pengajaran pengetahuan Agama Islam. Journal of Applied Research in Education, 15(1 \& 2), 43-58.

Wolters, C. A., \& Daugherty, S. G. (2007). Goal structures and teachers' sense of efficacy: Their relation and association to teaching experience and academic level. Journal of Educational Psychology, 99(1), 181-193. https://doi.org/10.1037/0022-0663.99.1.181

Xanthopoulou, D., Bakker, A. B., Demerouti, E., \& Schaufeli, W. B. (2007). The role of personal resources in the job demands-resources model. International Journal of Stress Management, 14(2), 121-141. https://doi.org/10.1037/1072-5245.14.2.121

Yin, H. B., Lee, J. C. K., Jin, Y. Le, \& Zhang, Z. H. (2013). The effect of trust on teacher empowerment: The mediation of teacher efficacy. Educational Studies, 39(1), 13-28. https://doi.org/10.1080/03055698.2012.666339

Yin, H., To, K. H., Keung, C. P. C., \& Tam, W. W. Y. (2019). Professional learning communities count: Examining the relationship between faculty trust and teacher professional learning in Hong Kong kindergartens. Teaching and Teacher Education, 82, 153-163. https://doi.org/10.1016/j.tate.2019.03.019

Zee, M., \& Koomen, H. M. Y. (2016). Teacher Self-Efficacy and Its Effects on Classroom Processes, Student Academic Adjustment, and Teacher Well-Being: A Synthesis of 40 Years of. Review of Educational Research, 1-35. https://doi.org/10.3102/0034654315626801

Zheng, X., Yin, H., \& Liu, Y. (2020). Are professional learning communities beneficial for teachers? A multilevel analysis of teacher self-efficacy and commitment in China. School Effectiveness and School Improvement, 32(2), 197-217. https://doi.org/10.1080/09243453.2020.1808484

Zohar, A. (2004). Higher order thinking in science classrooms: Students' learning and teachers' professional development. Kluwer Academic Publishers.

Zohar, A., \& Alboher Agmon, V. (2017). Raising test scores vs. teaching higher order thinking (HOT): senior science teachers' views on how several concurrent policies affect classroom practices. Research in Science and Technological Education, 1-18. https://doi.org/10.1080/02635143.2017.1395332

Zohar, A., Degani, A., \& Vaaknin, E. (2001). Teachers' beliefs about low-achieving students and higher order thinking. Teaching and Teacher Education, 17(4), 469-485. https://doi.org/10.1016/S0742-051X(01)00007-5

Zohar, A., \& Schwartzer, N. (2005). Assessing teachers' pedagogical knowledge in the context of teaching higher-order thinking. International Journal of Science Education, 27(13), 1595-1620. https://doi.org/10.1080/09500690500186592 